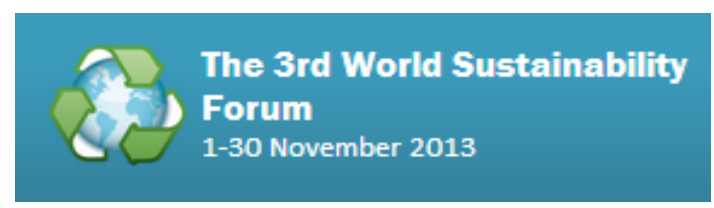

http://www.sciforum.net/conference/wsf3

\title{
Article
}

\section{Exergy Storage in the Ground}

\author{
Ron Tolmie $^{1, *}$ and Marc A. Rosen ${ }^{2}$ \\ ${ }^{1}$ Sustainability-Journal.ca, 217 Petrie Lane, Kanata, Ontario, K2K 1Z5, Canada \\ ${ }^{2}$ Faculty of Engineering and Applied Science, University of Ontario Institute of Technology, 2000 \\ Simcoe Street North, Oshawa, Ontario, L1H 7K4, Canada \\ E-Mails: tolmie129@rogers.com (R. T.); marc.rosen@uoit.ca (M. R.) \\ * Author to whom correspondence should be addressed; Tel.: +1-613-271-9543
}

Received:07 August 2013 / Accepted: 29 October 2013 / Published: 01 November 2013

\begin{abstract}
By adding a heat pump to an atmospheric energy heat store it becomes possible to transfer heat from the periphery of the store to its center. That does not materially increase the amount of heat being stored but it does increase the amount of stored exergy. It also makes it possible to achieve temperatures that are suitable for providing space heating and cooling without the need of using a second heat pump and if solar thermal energy is also utilized then such an integrated system can provide domestic hot water as well. If the exergy-boosting heat pump is controlled by the grid operator then such a store performs much like a giant electric battery from the point of view of the grid operator, so the one storage system concurrently serves two different purposes, providing storage capabilities for both heat and (in effect) for electricity.
\end{abstract}

Keywords: exergy; energy storage; ground energy. 


\section{Introduction}

The ability to store energy makes intermittent energy sources more useful, enables fixed output sources to handle variable loads, improves the efficiency of power grids, and increases the peak power supply capacity without needing to generate more power. In buildings we use energy in two forms: thermal energy for heating, cooling and domestic hot water, and electric energy for running equipment. Both forms of energy can in effect be stored in the ground using exergy storage systems.

An atmospheric energy ${ }^{1}$ heat store can store thermal energy extracted at ambient temperatures for later periods when it is needed. Adding a heat pump to an atmospheric energy heat store makes it possible to transfer heat from the periphery of the store to its center. That does not materially increase the amount of heat being stored but it does increase the amount of stored exergy and can provide temperatures suitable for providing space heating and cooling without the need of using an additional heat pump.

Figure 1. Prototype of the heat storage system.

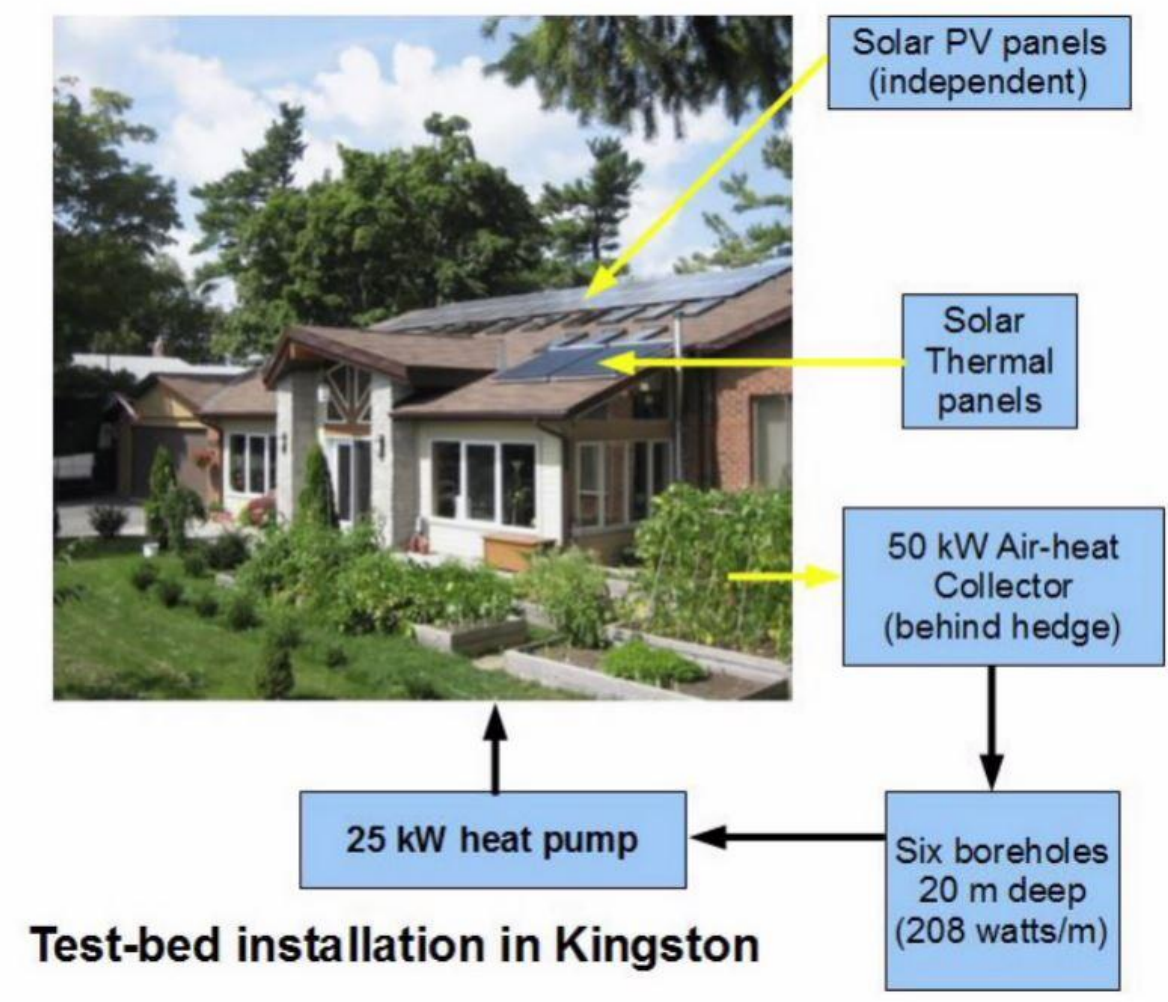

For the past four years the home of Volker Thomsen in Kingston, Ontario (see Figure 1) has been heated by using heat that is collected from the air in the summertime and transferred into the ground by a ring of boreholes containing heat exchange tubes ${ }^{2}$. Over a six month period that heat gradually migrates out to a second concentric ring of boreholes from which the heat can be extracted via a heat pump during the winter. The temperature of the ground around the outer ring is at or below the ambient ground temperature so there is no net heat flow out of the store, making it very energy efficient. The result is that most of the energy that is needed by the house is being extracted from the air - an energy source that has a virtually unlimited capacity ${ }^{3}$ - and the capital cost of the storage 
facility is modest because the total length of the boreholes is only about 5 metres per kilowatt of heating capacity ${ }^{4}$. The concept is particularly attractive for groups of homes such as all of the homes in a city block ${ }^{5}$, in which case such storage systems can be expanded to "store" electricity as well as heat.

These topics form the main focus of this paper, which examines options for exergy storage in the ground and relevant applications. The objective is to improve the understanding of the possible energy storage options and thereby to foster increased adoption of such measures.

\section{Methods: The Exergy Storage (ExS) System Concept}

When we refer to storing electricity what we generally mean is that the electricity is first converted into a different form, such as chemical energy stored in a battery or mechanical energy in a pumped hydro storage facility. In an exergy storage (ExS) system we convert the electricity to heat and store it in that form. Very little of the heat is lost in such an ExS concentric store but over the course of a year some of the heat will flow from the hot central zone to the cool outer zone and that represents a loss of some of the exergy of the two-zone pair. However, once heat extraction from the inner ring commences this loss stops for subsequent injections. During the winter the direction of heat flow in the ground is always in the direction of the extraction pipes so any heat injected into the ground at that time always remains close to the pipes. There is no mechanism for losing any of that stored heat or exergy except for a small loss at the ends of the boreholes.

Usually in electricity storage systems the stored energy is subsequently converted back into electricity but in this case the re-conversion is not necessary. We can use the energy in the form of heat so there is no conversion efficiency loss in the recovery step. Very nearly $100 \%$ of the input energy is stored in the ground, virtually none of the heat is lost during the storage period and almost $100 \%$ of the heat is recovered in the recovery step. What we have is a nearly perfect heat store that is also capable of delivering the heat at the temperature that is needed to heat the buildings. The electric power that was used by the exergy-boosting pump during the surplus power periods is also recovered via the demand reduction that occurs during periods of high power demand.

The Thompsen house (Figure 1) incorporates a buffer that smoothes out the abrupt ground loop temperature fluctuations that occur when the heat pump turns on. Over the past two years that buffer has been losing some of its electrical energy input to the heat loop and that is thermally tricklecharging the heat store. Since that extra heat is stored very close to the ground heat exchange pipes it can be recovered at a high rate on a cold night so the store acts like an energy battery that is being trickle-charged but that is capable of delivering heat at a high rate when the need arises.

These topics form the main focus of this paper, which examines options for exergy storage in the ground and relevant applications. The objective is to improve understanding of the possible energy storage options and thereby to foster increased adoption of such measures.

\section{Discussion}

\subsection{Features of the Exergy Storage System Concept}

The "storage" or "battery" described in the previous section has various interesting properties:

1. It can accumulate energy at a low rate and then deliver it at a high rate (or vice versa). 
2. During the period from October to April there is virtually no storage loss of newly injected heat because the direction of heat flow in the ground around the extraction tubes precludes such losses.

3. It handles high energy transfer rates, e.g. $10 \mathrm{~kW}(\mathrm{t})$ for a single house or $100,000 \mathrm{~kW}(\mathrm{t})$ for a housing development of 10,000 homes, etc.

4. Where the energy input is electrical and the output displaces a heating process that would otherwise be electrical the system functions like an electrical battery.

5. The rate and the timing of the heat pump operation can be controlled by a third party (with some simple procedures). For example, the power grid operator could control the heat pump so that it only operates at times when there is a surplus of power available. In Canada the peak power demand periods almost always coincide with periods of high thermal loads (for heating in the winter or cooling in the summer) and the magnitude of those thermal demands is much larger than the electric peak power demand so such stores are inherently capable of providing any likely storage capacity that might be needed.

6. The source of the heat for the "battery" does not need to be electrical. A solar thermal collector could be used instead, in which case the energy from the solar collector is efficiently utilized, stored with little loss, and is ultimately used for electrical demand reduction so the "battery" still functions like an electric battery from an electricity-storage point of view, with the solar collector being the source of the drive energy. The demand reduction achieved by such solar collectors can be much higher than the output of solar photovoltaic (PV) collectors; also, they are simpler and cheaper, and are part of an energy storage system. That can make this approach more attractive than using solar PV collectors. Moreover, the storage makes the use of the solar thermal collectors for the domestic hot water application more efficient as well because they require less electric backup.

7. The cost per MW of providing thermal storage is normally much smaller than the cost of adding new generation capacity so it is often cheaper to add storage to a grid system rather than to add generators ${ }^{6}$.

8. The cost of the distribution grid itself can be greatly reduced because there is less need to handle high-power, long-distance power fluctuations once local electricity storage is utilized.

9. Where the peak power demand coincides with the peak thermal demand (as it does in Canada) the use of thermal storage can reduce the need to use fossil-fuelled peaking stations.

10. The use of exergy storage systems could free up the considerable quantities of electricity that are presently being used for cooling, heating and domestic hot water (DHW) applications, enabling us to reduce or retire the use of fossil fuels for power generation, and eventually to do the same for nuclear power.

11. Because the heat store has three zones that operate at nearly the temperatures that are needed to heat and cool the house and to provide domestic hot water it is feasible to provide those services even if the power grid fails. Only a small amount of power from a standby source is needed to operate the circulation pumps in that event.

12. The storage concept can also be applied to the storage of cold extracted from the air in the winter, a variant that is useful for large buildings for which the dominant need is cooling rather 
than heating. The Enwave system in Toronto already uses storage of winter cold extracted from the air for this application on a large scale.

Conceptually the use of exergy stores can enable us to redesign our energy supply systems for both thermal and electrical applications. Heat and cold extracted from the air and hydro, wind and solar energy would become our primary energy sources. The exergy components of such a supply system are almost invisible, silent and sustainable and produce no pollution or greenhouse gas (GHG) emissions. The question is how can we convert the above theoretical advantages into working systems?

\subsection{ExS system Design}

The design of the Thomsen house provides most of the answers, although it presently has only a small exergy storage capacity. That design can handle the storage of heat or cold and it can be modified to meet the needs of small buildings (or groups of homes) or large buildings. It primarily needs to be modified to provide exergy storage on a much larger scale. Figure 2 shows the current design (called an atmospheric energy (AE) system) and Figure 3 shows a modified design that adds the exergy storage (ExS) capacity. Note that the primary difference is that the heat pump has been moved from the output to a position where it extracts heat from the outer ring and moves that heat to the inner ring. The systems are otherwise almost identical, employing the same method of trapping the heat and the same heat exchange hardware. (Many of the details are covered elsewhere) ${ }^{\mathbf{7 , 8}}$.

Figure 2. Atmospheric energy system.

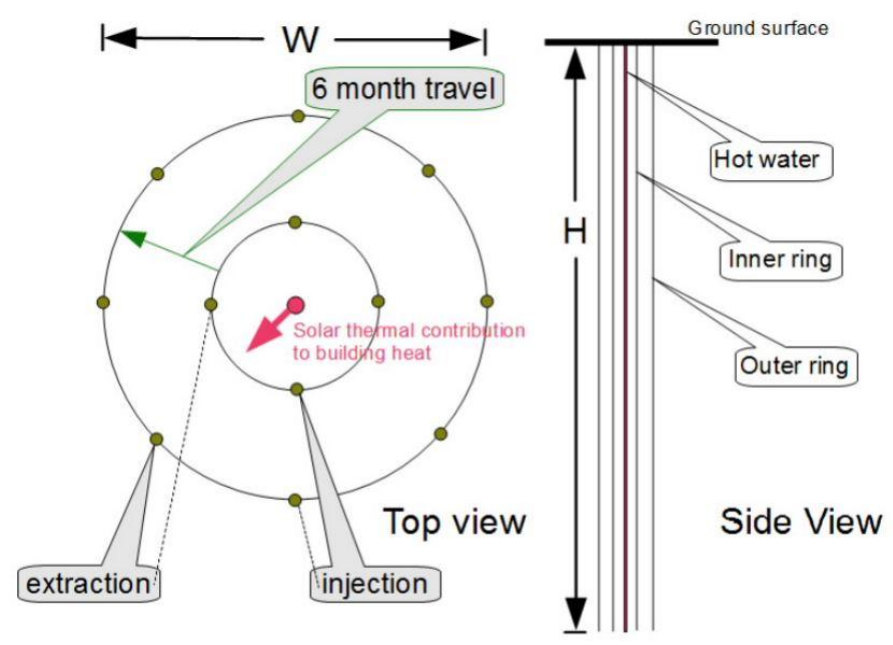

13 Borehole Concentric Heat Store

Figure 3. Exergy storage system. 


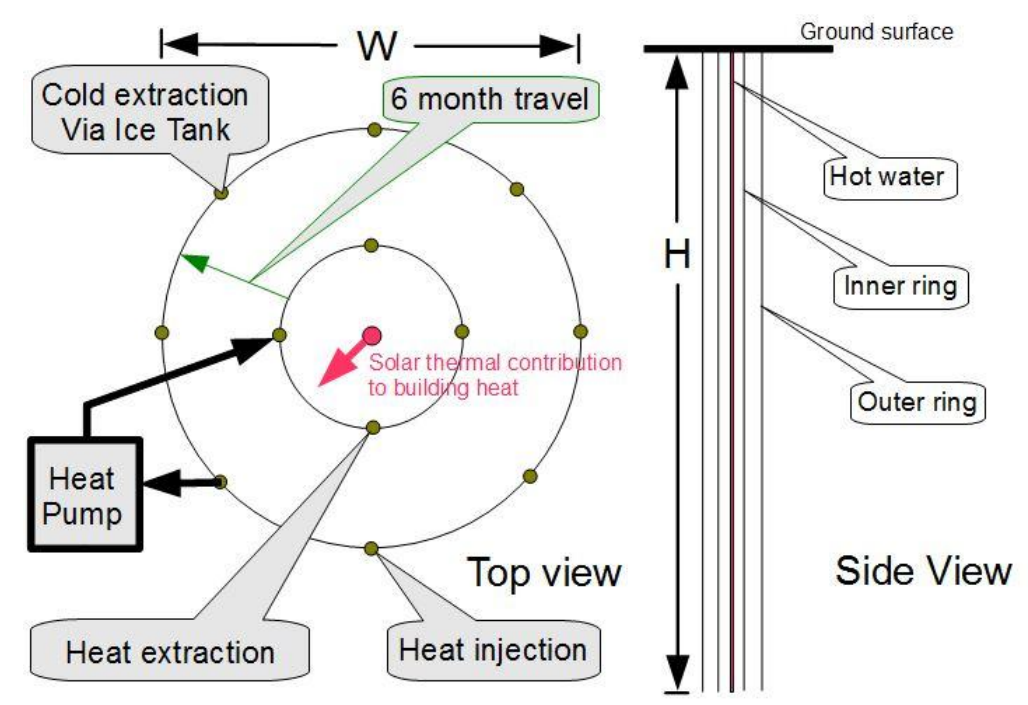

13 Borehole Concentric Heat Store

Figure 4. Air-heat exchanger. The $50 \mathrm{~kW}$ air-heat exchanger transfers heat into the ground loop of the test-bed system.

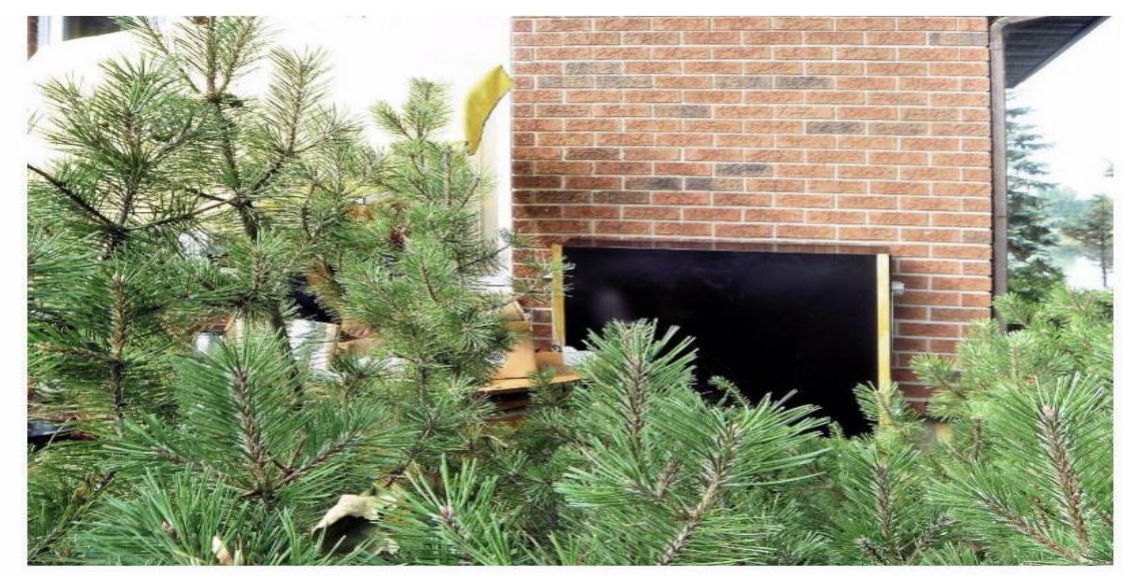

In the Thomsen house the heat is extracted from the air via the air-heat exchanger (Figure 4) and is then injected into the central ring. By the winter the heat flowing in the ground has reached the outer ring, from which it is extracted and used to heat the house, thus maintaining the local ground temperature at approximately its ambient value. Just before mid winter the inner ring is connected to the heat extraction loop so that the heat pump draws heat from both rings. By the spring most of the heat from the whole storage zone has been extracted so the injection process is started again for the coming winter. The Thomsen house has a solar thermal collection system of conventional design that provides the DHW. The link shown in the drawing provides the heat for a small scale exergy input (which presently uses an electric supply) but that will require a future additional solar thermal collector panel to provide both the exergy input and a larger fraction of the DHW demand. Adding storage solves the problem of what to do with the excess solar heat produced in the summer. Although it is not shown, this system uses an ice tank for diurnal storage, a design feature that is carried over to the exergy storage design, but in the ExS case it functions in the summer rather than the winter. 


\subsection{Adding Exergy Storage}

For the exergy storage system the air-heat injection is moved to the outer ring. As heat is added to that ring by the air-heat injector the heat pump moves the heat to the inner ring so that the outer ring temperature remains constant. By the end of the summer the inner core will be much hotter than that of the AE design because the heat pump is capable of delivering a higher temperature than the air-heat exchanger. The design objective is to maintain that core temperature at $40^{\circ} \mathrm{C}$ or higher so that heat can be extracted from the core to heat one or more buildings without needing heat pumps to boost the temperature. That objective would be difficult to meet with the heat pump alone so solar heat is injected into the core, again using a spacing that will ensure that the heat reaches the extraction ring by mid winter, maintaining a high enough heat flow rate to help sustain the $40{ }^{\circ} \mathrm{C}$ value.

In the summer the air-heat injection and the heat-pump's exergy pumping operations do not have to operate at the same time. The ground has ample storage capacity to handle either a temporary surplus or deficit of heat. That makes it possible for the grid operator and the building operator to function independently, providing they meet their seasonal quotas. The grid operator can run the heat pump only when there is a surplus of electricity available. The air-heat injector will operate as required to maintain the ground temperature at the desired value. Since that parameter is completely controllable the recovery loop temperature can be maintained at $4{ }^{\circ} \mathrm{C}$ for the June to September period. That is a temperature that is commonly used for cooling systems in buildings so the loop can be used without needing a heat pump. An ice tank ${ }^{9}$ located at the input of the ground loop provides short term storage so the average ground temperature around the outer loop would fall by only a few degrees below the ambient ground temperature. So long as the $40^{\circ}$ objective is met for the inner ring the buildings can likewise be heated without needing heat pumps. If the core is maintained at a temperature approaching $60{ }^{\circ} \mathrm{C}$ a conventional water tank with electric regulation can be used for domestic hot water with relatively little electricity consumption. Thus all three thermal loads can be met without the need of using power except for the relatively small consumption of the circulation pumps. That represents a large demand reduction that occurs at the times of maximum grid power demand.

If those temperature objectives are met then the buildings will not require either heat pumps or furnaces. Since copious amounts of heat are available from this type of system the buildings will not require super insulation or complex heat recovery systems either, making it feasible to retrofit exergy systems to the existing housing stock - a fundamental requirement if Canada is to achieve the needed GHG reductions within a reasonable time frame.

During the winter some of the heat injected during the summer will reach the outer ring and will need to be re-pumped back into the center. That does not mean that any energy is lost. To lose energy heat would have to flow out of the store and into the surrounding ground, which does not happen. However it does represent a reduction in the amount of heat that can be injected during the summer. The recycling operation is essential to the proper functioning of the system. It provides one of the mechanisms for maintaining the central temperature at the required $40{ }^{\circ} \mathrm{C}$ and also the mechanism that the grid operator needs to be able to accumulate electricity in the "storage battery" if, for example, the wind is supplying surplus power during the winter. 
At that time heat is being withdrawn steadily from the $40{ }^{\circ} \mathrm{C}$ zone to heat the buildings. Much of that extracted heat will be replaced by the steady flow of heat from the storage zone into the extraction boreholes but that replacement is augmented by solar heat coming from the core (the amount can be defined at the design stage) and the heat being pumped from the periphery, which can be adjusted to provide temperature regulation. The option is also available to extract extra heat directly from the core to superheat the extraction loop going to the buildings so there is no danger that the space heating will fail if unexpectedly high loads are encountered. Extracting heat from the core does not jeopardize anything but the DHW efficiency factor - the DHW system would tend to revert to using some electrical heat, operating just like normal hot water tanks do now.

Note that the exergy pump will normally be operating at night, when the greatest heat load occurs, and that its output temperature will be well above the required $40{ }^{\circ} \mathrm{C}$. Some of its heat output can therefore be coupled directly to the heating line for the buildings with the balance going to the ground. The result is that heat is withdrawn and utilized from both the inner and outer rings, just as in an AE system, and the inner ring's ground temperature is stabilized so that it can supply the heat when the grid controller does not need to operate the exergy pump. The two functions need to be only very loosely synchronized because the ground has such a large storage capacity.

Throughout the year the normal pattern for electricity consumption is that it is high during the daytime when people are active but low at night when they are sleeping or less active. For that reason it is desirable for the exergy-boosting heat pump to operate at night at all times of the year, with the dwell time being modulated to handle the fluctuations in both the energy supply and the energy demand. The grid operator would prefer never to run the heat pump at any time except when surplus power is available, and that dilemma is not likely to happen, but the options are open to extend its dwell time in the event of unusual space-heating loads and/or to fall back on the use of the stored solar heat in the core, neither of which creates serious problems for either party. If the space-heating load is smaller than anticipated the consequence would be that the inner ring temperature would be a little higher than the nominal $40{ }^{\circ} \mathrm{C}$, which would be immaterial. If the annual load changes because buildings are added or taken out of service the storage system would be rebalanced by injecting more or less heat in the summer.

\subsection{Costs}

The primary expense in building the exergy stores will be the cost of the boreholes and their heat exchangers, grouting, trenching, etc. The cost of an ExS store will depend on the application but if it is comparable to that of an AE system (which needs $5 \mathrm{~m}$ of borehole per $\mathrm{kW}$ of capacity) the cost would be several times less than the cost of the boreholes for a conventional ground source heat pump of comparable capacity. The primary problem is likely to be sorting out who should pay for those costs. The stores provide for two independent functions that will be manged by two different parties with very little need for interactions. Both will gain important advantages for their own needs via systems that are inexpensive to build and inexpensive to operate, but they will have to agree on a method for sharing the costs.

\section{Conclusions}


ExS and AE systems open up the potential for using heat and cold extracted from the air on a large scale and they can also make use of the air-conditioner output heat that is presently being rejected as waste into the atmosphere. Storage of electricity and heat would reduce the future need for increased power generation and provides a means of making better use of intermittent power sources like wind. ExS systems eliminate the need for both furnaces and AC heat pumps in homes, and reduce the power loads during peak demand periods to zero except for the small circulation pump loads. A major consequence is a large reduction in the GHG emissions from the buildings sector if the concept is widely applied.

\section{Acknowledgments}

The construction of the prototype system was managed by Volker Thomsen, who made many useful contributions to the design. Building the prototype required a great deal of hard work and a strong dedication to the objectives. The performance of the heat store was monitored using a multichannel data logger that was programmed by Dave Wilson, who handled the data reduction.

\section{Conflict of Interest}

The authors declare no conflict of interest.

\section{References and Notes}

1. R. Tolmie, "Sustainable, Resilient Municipal Energy Systems", 7th World Wind Energy Conference 2008, Kingston, Ontario (also available in the July, 2008 issue of www.sustainabilityjournal.ca).

2. R. Tolmie, "Concentric Ring Heat Exchangers", GeoExchange Coalition/CANSIA workshop, Toronto, Jan, 2013. www.geoexchange.ca/en/renewable_heat_policy_technology_integrating_s_wk3073.php.

3. Introduction to the Atmosphere, University Corporation for Atmospheric Research, Boulder, CO, www.ucar.edu/learn/1_1_1.htm.

4. R. Tolmie, "Using Heat Storage for Electricity Demand Management", 2013 Canadian GeoExchange Conference, Vancouver.

5. Drake Landing District Heating, www.dlsc.ca/district.htm.

6. I. Dincer, M.A. Rosen, "Thermal Energy Storage and Energy Savings", Chapter 5 in "Thermal Energy Storage: Systems and Applications”, 2nd ed., Wiley, London, 2011.

7. I. Dincer, M.A. Rosen, "Thermal Energy Storage, Systems and Applications", 2nd ed., Wiley, London, 2011.

8. Www.sustainability-journal.ca, Jan 2007- present.

9. Ice Storage Air Conditioning”, Wikipedia. Accessed 13 October 2013. 
(C) 2011 by the authors; licensee MDPI, Basel, Switzerland. This article is an open access article distributed under the terms and conditions of the Creative Commons Attribution license (http://creativecommons.org/licenses/by/3.0/). 